\title{
IS TWO DOSES OF ANTIBIOTIC IN UNCOMPLICATED ACUTE APPENDICITIS SUFFICIENT?
}

\author{
Shanta Basavaraj Patil ${ }^{1}$, Keerti Mali Patil
}

${ }_{1}^{1}$ Associate Professor, Department of General Surgery, Mahadevappa Rampure Medical College, Gulbarga, Karnataka, India. 2Postgraduate Student, Department of General Surgery, Mahadevappa Rampure Medical College, Gulbarga, Karnataka, India.

\section{ABSTRACT}

\section{BACKGROUND}

Medical descriptions of right lower quadrant peritonitis, perityphlitis, appeared more than 500 years ago. Acute appendicitis is one of the most common acute surgical illnesses that every surgeon comes across and surgical intervention is the main stay of treatment. Use of single dose pre and post-operative antibiotics instead of 5 days course for treating patients with uncomplicated acute appendicitis post appendectomy showed same results. Hence this study is undertaken to study effectiveness of the outcome of use of two doses of antibiotic therapy with those of regular 5 days antibiotic course in patients undergoing open appendectomy who presented to Basaveshwara Teaching and General Hospital, Gulbarga.

\section{METHODS}

This clinical, randomized control trial was conducted from September 2016 until September 2018. The trial enrolled 100 patients aged 15 to 32 years with uncomplicated acute appendicitis confirmed by clinical evaluation and radiographic study.

\section{RESULTS}

There were 100 patients in the surgical study group. The mean age of the patients was $22.90 \pm 4.93$. The results of study group and control group on evaluation didn't show any significant difference. The results of this study concluded that two doses of antibiotics were as effective as conventional five-day antibiotics dose yielding same outcome.

\section{CONCLUSIONS}

As clinical outcome in both groups of our study were not statistically significant. And as costs in the two-dose group is less than that of five-day doses group, prescription of two dose of prophylactic antibiotics prior to surgery of uncomplicated acute appendicitis is sufficient. Hence, we conclude the same from above study.

\section{KEY WORDS}

Acute Appendicitis, Uncomplicated Appendicitis, Prophylaxis Antibiotics, Open Appendectomy

HOW TO CITE THIS ARTICLE: Patil SB, Patil KM. Is two doses of antibiotic in uncomplicated acute appendicitis sufficient? J. Evolution Med. Dent. Sci. 2019;8(23):1858-1861, DOI: 10.14260/jemds/2019/408

\section{BACKGROUND}

Medical descriptions of right lower quadrant peritonitis, perityphlitis, appeared more than 500 years ago. Inflammation of appendix was conclusively demonstrated to cause this condition by Reginald Fitz in 1886.

About two third (2/3) of patients are men and two third $(2 / 3)$ of patients age from 15-44 years old. Nevertheless, anyone can be infected undermining the age.[1,2]

One of the stages of acute appendicitis is uncomplicated appendicitis i.e., a hyperaemic supportive appendicitis, which is the most prevalent stage in patients diagnosed with appendicitis. Supportive appendicitis is a condition was in inflammation of appendix without gangrene is seen.

The major treatment for acute appendicitis is surgery. Occasionally, the diagnosis is complex, and further diagnostic work-up is necessary. Appendectomy is carried out either by means of an open incision or via laparoscopy, [1-3] here in our study we have under taken open appendectomy.

'Financial or Other Competing Interest': None.

Submission 09-05-2019, Peer Review 30-05-2019,

Acceptance 01-06-2019, Published 10-06-2019.

Corresponding Author:

Dr. Keerti Mali Patil,

H. No. 10-934/56, Sharan Nilya,

Mahalaxmi Nagar,

Opposite Fire Station,

Gulbaraga, Karnataka, India.

E-mail: patilkeerti29@gmail.com

DOI: $10.14260 /$ jemds $/ 2019 / 408$

\section{(c) $(1)$}

Medical management before and after the surgery, has an important impact on the treatment. Almost all studies suggest that consumption of antibiotics in acute appendicitis as prophylaxis or as a supplementary treatment in complicated cases (e.g. Perforated, Abscess and Phlegmon) is a proven requirement.[1-4]

In acute appendicitis cases that have not received prophylactic antibiotics before surgery, over $25 \%$ wound infection is reported. Antibiotics prescription prior to surgery is considered to be effective in reducing the infectious complications of appendectomy.

As a result, most surgeons prescribe antibiotics before surgery for patients diagnosed with appendicitis.[1-3, 4-7] Cohort studies show that two doses of antibiotic treatment is feasible and safe Furthermore; there is a growing global health issue of bacterial resistance. Antimicrobial resistance is a natural biological outcome of antibiotic use and antibiotic over- treatment speeds up this 1 process. Hence, restricting antibiotic therapy is warranted, as pointed out in a report by the World Health Organization.

Antibiotic used in this study depended on the fact that Sixty percent of intra luminal micro floras aspirated from inflamed appendix are anaerobic bacteria whereas only $25 \%$ of the normal appendix luminal contents are anaerobes and appendicitis is a poly microbial infection. ${ }^{[1]}$

Aerobic flora of the skin alone or with other pathogens leads to a high percentage of surgical site infections. Moreover, gram-negative enteric bacteria are the most probable reasons of wound infection after appendectomy. 
Cephalosporins have an extended spectrum anti-bacterial effect against gram-positive cocci and gram-negative enteric bacteria and are the most commonly utilized antibiotics in prophylaxis and treatment. $[1,3]$

Acute appendicitis is one of the most common surgical emergencies in children and adults worldwide. Therefore, following perioperative antibiotic prophylaxis, guidelines recommend postoperative antibiotics for complex appendicitis. Currently, there is no consensus on the duration of postoperative antibiotic treatment. However, it may be safe to stop intravenously administered (IV) antibiotic treatment earlier than 5 days, when a patient meets defined discharge criteria (Patient is afebrile, has a normal leukocyte count, has resumed oral intake).

This study aims to evaluate efficacy of a restrictive postoperative antibiotic course as compared to standard regimen for complex appendicitis.

\section{Aims and Objectives \\ The primary objective of this study is to evaluate the efficacy and safety of discontinuing antibiotic treatment after $48 \mathrm{~h}$, compared to completing a standard course of 5 days \\ After appendectomy for uncomplicated acute appendicitis. It is hypothesized that a 48 - $h$ course is non- inferior to 5 days and will not result in an increase of infectious complications and mortality. A secondary aim is to evaluate length of hospital stay and cost-effectiveness.}

\section{METHODS}

\section{IEC Clearance}

This study was conducted after getting the approval from the hospital ethical management committee after giving details about the study and its probable valuable outcome.

\section{Study Design}

Study is design included 100 patients diagnosed with acute uncomplicated appendicitis, after meet the eligibility criteria were grouped as Group I and Group II both were started on prophylactic antibiotics $24 \mathrm{hr}$., before and post-surgery Group I was given only one dose of antibiotics and Group II for 5 days.

\section{Study Place}

Patients who presented to Emergency department of department of General surgery in Basaveshwara teaching and general hospital, Gulbarga, Karnataka.

\section{Sample Size Calculation}

100 patients were taken under for study, they were randomised and divided into a study group and a control group; 50 each in both the groups. Study group was subjected to two dose of antibiotics that is pre-op dose of antibiotic and post-operative single dose of IV antibiotics

Control group on other hand received pre-op dose of antibiotics and postoperative five days of IV antibiotics course and the outcome was calculated.

\section{Inclusion Criteria}

Patients of at least 15 years till 32 years of age who are scheduled to undergo surgery for suspected acute appendicitis will be approached for participation in the study. If a complex appendicitis is diagnosed intraoperatively, patients are eligible for inclusion. A complex appendicitis is defined as a gangrenous and/or perforated appendicitis or any appendicitis in presence of an IAA (Intra-abdominal abscess). Written informed consent is preferably obtained before surgery, but may be Obtained postoperatively as long as inclusion and randomization is performed within $24 \mathrm{~h}$ after surgery.

\section{Exclusion Criteria}

- Unable to give informed consent (Language barrier, legally incapable).

- Interval appendectomy.

- Appendicular lump.

- Appendicular abscess.

- Clinical suspicion of severe sepsis.

- Conservative treatment of acute appendicitis.

- American Society of Anesthesiologists (ASA) score IV or not able to undergo surgery.

- Known allergy or other contraindication to study medication*

- Immunocompromised patients*

- Pregnancy.

- Concurrent use of antibiotics for other indication*

- Appendicular infiltrate not amendable for appendectomy.

\section{Data Collection and Management}

A data manager from hospital will carry out the data collection in collaboration with the trial coordinator. Baseline demographics, as well as preoperative, intraoperative and postoperative variables, will be collected from the medical records, randomization was carried out by flipping of coin.

\section{Intervention}

Ravari et al.[8] showed that single dose of oral metronidazole prior to operation can provide a sufficient prophylaxis for non-perforated appendicitis, when compared to single dose of intravenous (IV) metronidazole before surgery. Kumarakrishnan et al.[9] showed that the combination of cefotaxime-metronidazole had the lowest wound infection rate compared to metronidazole- gentamycin and metronidazole-ciprofloxacin.

Salam et al.[10] showed that prophylactic cefoxitin or piperacillin were similarly effective in minimizing the rate of wound infections.

Participants will be randomized (1:1) to receive either: (1) a short course of $48 \mathrm{~h}$ or (2) a standard 5-day course of postoperative antibiotic treatment.

All patients receive IV antibiotics before and after appendectomy cefuroxime/metronidazole (three times a day, $1500 / 500 \mathrm{mg}$ ), according to our Antibiotic policy. In the control group the IV antibiotics are continued for five more days (A switch to an oral formula is not allowed).

\section{Assessment of Outcome}

The analysis of this study was done on the bases of outcome in terms of Erythema, seroma formation, post-operative fever, wound infection, and Intra-abdominal abscess in both control and study group. 
RESULTS

\begin{tabular}{|c|c|c|c|c|c|c|}
\hline \multirow{2}{*}{ Age } & \multicolumn{2}{|c|}{ Group I } & \multicolumn{2}{c|}{ Group-II } & \multicolumn{2}{c|}{ Total } \\
\cline { 2 - 7 } & No. & $\mathbf{\%}$ & No. & $\mathbf{\%}$ & No. & $\%$ \\
\hline $15-20$ & 16 & 32.0 & 14 & 28.0 & 30 & 30.0 \\
\hline $20-25$ & 11 & 22.0 & 20 & 40.0 & 31 & 31.0 \\
\hline $25-30$ & 15 & 30.0 & 11 & 22.0 & 26 & 26.0 \\
\hline $30-35$ & 8 & 16.0 & 5 & 10.0 & 13 & 13.0 \\
\hline Total & 50 & 100.0 & 50 & 100.0 & 100 & 100.0 \\
\hline Mean \pm SD & $23.36 \pm 5.33$ & $22.45 \pm 4.54$ & $22.90 \pm 4.93$ \\
\hline $\begin{array}{c}\text { t-test value } \\
\text { p-value \& } \\
\text { sig. }\end{array}$ & \multicolumn{7}{|c|}{ Table 1. Age Wise Distribution of Cases } \\
\hline \multicolumn{1}{|c|}{} & 0.959 p $>0.05$ NS \\
\hline
\end{tabular}

In this study of 100 patients were group I control group and is study group and group II study group; the mean age of group I being $23.36 \pm$ 5.33 and that of group II is $22.45 \pm 4.54$

Study observe that, there was no statistical significance difference of mean age among group-I and group.

\begin{tabular}{|c|c|c|c|}
\hline \multirow{2}{*}{ Sex } & Group I & Group-II & Total \\
\cline { 2 - 4 } & Number (\%) & Number (\%) & Number (\%) \\
\hline Male & $31(62.0 \%)$ & $30(60.0 \%)$ & $61(61.0 \%)$ \\
\hline Female & $19(38.0 \%)$ & $20(40.0 \%)$ & $39(39.0 \%)$ \\
\hline Total & $50(100.0 \%)$ & $50(100.0 \%)$ & $100(100.0 \%)$ \\
\hline $\begin{array}{c}\text { Chi-square test. } \\
\text { P- value \& sig }\end{array}$ & $\mathrm{X}^{2}=0.042 \mathrm{P}>0.05 \mathrm{NS}$ \\
\hline \multicolumn{3}{|c|}{ Table 2. Sex Wise Distribution of Cases } \\
\hline There was no statistical significance difference of sex among group-I and \\
group-II (P>0.05) \\
\hline
\end{tabular}

\begin{tabular}{|c|c|c|c|c|}
\hline \multirow{2}{*}{\multicolumn{2}{|c|}{ Variables }} & $\begin{array}{l}\text { Group I } \\
\text { (5 Dose) }\end{array}$ & $\begin{array}{l}\text { Group-II } \\
\text { (2 Dose) }\end{array}$ & \multirow{2}{*}{$\begin{array}{c}\text { Chi-Square Test } \\
\text { p-Value \& Sig. }\end{array}$} \\
\hline & & Number (\%) & $\frac{\text { (2 Dose })}{\text { Number }(\%)}$ & \\
\hline \multirow{2}{*}{ Erythema } & Yes & 17 & 18 & $X^{2}=0.044$ \\
\hline & No & 33 & 32 & $\mathrm{P}>0.05 \mathrm{NS}$ \\
\hline \multirow{2}{*}{ Seroma } & Yes & 13 & 12 & $\mathrm{X}^{2}=0.053$ \\
\hline & No & 37 & 38 & $\mathrm{P}>0.05 \mathrm{NS}$ \\
\hline \multirow{2}{*}{ Fever } & Yes & 2 & 3 & $\mathrm{X}^{2}=0.213$ \\
\hline & No & 48 & 47 & $\mathrm{P}>0.05 \mathrm{NS}$ \\
\hline \multirow{2}{*}{$\begin{array}{c}\text { Wound } \\
\text { infection }\end{array}$} & Yes & 2 & 3 & $\mathrm{X}^{2}=0.213$ \\
\hline & No & 48 & 47 & $\mathrm{P}>0.05 \mathrm{NS}$ \\
\hline \multirow{2}{*}{ IAA } & Yes & 0 & 1 & $\mathrm{X}^{2}=1.011$ \\
\hline & No & 50 & 49 & $\mathrm{P}>0.05 \mathrm{NS}$ \\
\hline \multicolumn{5}{|c|}{ Table 3. Comparison of Variables Between Group-I and Group-II } \\
\hline & & NS $=$ Not & nificant & \\
\hline
\end{tabular}

Diagnosis of these outcomes were done by clinical examination, inflammatory changes of the skin/redness of skin around suture line Seroma formation, as the serous discharge from the wound noted after 5-7 days.

Any post-operative episodes of fever secondary to wound infection was noted and intra-abdominal abscess. Patients were observed for a period of 7 day to evaluate the outcome of this study, susceptible patients were asked to follow-up regularly, discharge of these patients was on basic evaluation like contamination of the wound, post-operative fever, sustaining oral intake and regular bowel movements.

\section{Statistical Analysis}

The analysis outcome was calculated based on the observation made in both the groups in terms of erythema, seroma, wound infection, post-operative fever, and lastly in an abdominal abscess. These complications were noted in both the participating groups and they were analysed statistically.
In the Study group; one patient was found to be diagnosed with intra-abdominal abscess, apart from this no other significant difference was found in these two groups.

Study reveals that, there was no statistical significance difference of Erythema positive cases, seroma positive cases, fever present cases, wound infected cases and IAA presents cases among group-I and group-II ( $\mathrm{P}>0.05)$

\section{DISCUSSION}

Acute appendicitis is one of the most commonly encountered surgical emergencies, especially by junior doctors on call, with emergency appendectomy making up $10 \%$ of all emergency abdominal surgeries.[11,12]

The word appendicitis refers to inflammation of appendix vermiform. The literal meaning of appendix is an appendageanything that is attached to a large or a major part as a tail or a limb. The Latin word vermiform means worm like structure.[13]

In 1735, on December 6th, Claudius Amyand performed the first appendicectomy.[13]

Mcburney in Newyork, in 1889, gave description of clinical features of acute appendicitis and pioneered the removal of acutely inflamed appendix before perforation occurred and also devised the muscle splitting incision (Grid iron), named after him.[13]

Acute appendicitis is one of the most common surgical emergencies. The diagnosis of acute appendicitis is based on clinical history, examination combined with investigations.[13]

Appendicitis is thought to be due to luminal obstruction. The appendix is vulnerable to obstruction owing to its small lumen.

Common causative organisms are E.coli, Streptococcus viridans, Pseudomonas aeruginosa, Bacteroides fragilis.[13]

Patients usually present with vague abdominal pain that is most commonly periumbilical in origin. Anorexia is often present, as is nausea with or without vomiting.

As the condition progresses and the appendiceal tip becomes inflamed, resulting in peritoneal irritation, the pain localizes to its classic location in the right lower quadrant. Tachycardia and mild dehydration are often present. Fever may also be present.

Abdominal examination typically reveals a quiet abdomen with tenderness and guarding on palpation of right lower quadrant. Tenderness is classically over McBurney's point. Rovsing sign, psoas sign and obturator sign may be positive.

Leukocytosis is present in $90 \%$ of the cases. Urine analysis typically normal. USG of the abdomen may show inflamed appendix. Sensitivity is reported to be $78 \%$ to $83 \%$ and specificity $83 \%$ to $93 \%$.

\section{CT Scan}

Highly effective and accurate with sensitivity of $90 \%$ to $100 \%$ and specificity of $91 \%$ to $99 \%$, but the drawback being its high cost. 14

Once diagnosed surgery is the mainstay of the treatment and use of antibiotics to aid better outcome is needed, use of these antibiotics in an effective way and to avoid antibiotic abuse, medical expenditure and ultimately preventing antibiotic resistance; the prophylactic antibiotics need to be selected carefully depending on the facts such as- 
- Avoidance of the antibiotic that can cause allergy.

- Active against pathogen most likely to contaminate the surgical site.

- Use of Narrow spectrum antibiotic.

- Cost, safety \& ease of administration antibiotic prophylaxis is just one of many actions taken to help reduce the rate of surgical site infections.

- $\quad$ Other preoperative actions include.

- Basic infection control strategies.

- Instrument sterilization.

- Patient's skin preparation.

- Pharmacokinetic profile.

- Hospital resistance pattern.

Antibiotic prophylaxis is just one of many actions taken to help reduce the rate of surgical site infections. Other preoperative actions include basic infection control strategies, instrument sterilization, patient's skin preparation are all equally important to prevent the infection and this aids in outcome too.

Different studies have been conducted and the debt is still going to know if two courses of antibiotics or regular course of five-day antibiotics is better.

In this present study, 100 cases of uncomplicated acute appendicitis attending BTGH emergency from September 2016 to September 2018 were included with age ranging 1532 years, who underwent open appendectomy and the results of this study were evaluated in terms of erythema, seroma, fever wound infection, and intra-abdominal abscess. The results of this study concluded that two doses of antibiotics as effective as conventional five day antibiotics dose yielding same outcome. The results were similar to that of the study conducted by Van den Boom et al. [15] Who conducted a study on use "Two versus five days of antibiotics after appendectomy for complex acute appendicitis (APPIC): study protocol for a randomized controlled trial 'of A nationwide prospective cohort study from the Netherlands in 2014 showed that in most patients $(78 \%)$ antibiotics were given for 5 days or more after surgery for complex appendicitis. The authors concluded that 3 days of antibiotics led to a similar rate of infectious complications.

It should be noted that acute appendicitis occurs in young and middle age groups and often patients are healthy people without underlying disease; so, feeding and hospital discharge is possible after a short period after surgery. In this study, antibiotic consumption after surgery did not have any particular effects in patient discharge delay. Since all our patients were follow up, there was no post-surgery infection and any such indication for future antibiotic use. Since our study is similar to that of the study conducted about in terms of use of prophylactic antibiotics, the use of two dose antibiotic in our study proved to be useful.

\section{CONCLUSIONS}

As clinical outcome in both groups of our study were not statistically significant, and as costs in the two-dose group is less than that of five-day doses group, prescription of two dose of prophylactic antibiotics prior to surgery of uncomplicated acute appendicitis is sufficient.

\section{REFERENCES}

[1] Brunicardi F, Anderson D, Billiar T, et al. Schwartz's Current practice of general surgery (e-book). McGrawHill Professional 2014.

[2] Townsend Jr CM, Beauchamp RD, Evers BM, et al. Sabiston Textbook of Surgery. Elsevier Health Sciences 2012.

[3] Zinner M, Ashley SW. Maingot's Abdominal operations. $11^{\text {th }}$ edn. McGraw-Hill Publishing 2007.

[4] Hawkins RB, Levy SM, Senter CE, et al. Beyond surgical care improvement program compliance: antibiotic prophylaxis implementation gaps. Am J Surg 2013;206(4):451-6.

[5] Wray CJ, Kao LS, Millas SG, et al. Acute appendicitis: controversies in diagnosis and management. Curr Probl Surg 2013;50(2):54-86.

[6] Coakley BA, Sussman ES, Wolfson TS, et al. Postoperative antibiotics correlate with worse outcomes after appendectomy for non-perforated appendicitis. J Am Coll Surg 2011;213(6):778-83.

[7] Enzler MJ, Berbari E, Osmon DR. Antimicrobial prophylaxis in adults. Mayo Clinic Proceedings 2011;86(7):686-701.

[8] Ravari H, Jangjoo A, Motamedifar J, et al. Oral metronidazole as antibiotic prophylaxis for patients with non-perforated appendicitis. Clin Exp Gastroenterol 2011;4:273-6.

[9] Kumarakrishnan S, Srinivasan K, Sahai A, et al. A trial of various regimens of antibiotics in acute appendicitis. Trop Gastroenterol 1997;18(4):177-9.

[10] Salam IM, Abu Galala KH, el Ashaal YI, et al. A randomized prospective study of cefoxitin versus piperacillin in appendicectomy. J Hosp Infect 1994;26(2):133-6.

[11] Kumar V, Cotran RS, Robbins SL. Appendix. In: Robbin's Basic pathology. $5^{\text {th }}$ edn. London: WB Saunders 1992: p. 520.

[12] Pal KM, Khan A. Appendicitis: a continuing challenge. J Pak Med Assoc 1998;48(7):189-92.

[13] Prystowky JB, Pugh CM, Nagle AP. Current problems in surgery. Appendicitis. Curr Probl Surg 2005;42(10):688-742.

[14] Parks NA, Schroeppel TJ. Update on imaging for acute appendicitis. Surg Clin North Am 2011;91(1):141-54.

[15] Van den Boom AL, de Wijkerslooth EMI, Van Rosmalen J, et al. Two versus five days of antibiotics after appendectomy for complex acute appendicitis (APPIC): study protocol for a randomized controlled trial. Trials 2018;19(1):263. https://doi.org/10.1186/s13063-018-2629-0. 